\title{
Effects of Ten Antibiotics on Seed Germination and Root Elongation in
}

Three Plant Species

Archives of Environmental Contamination and Toxicology

ISSN 0090-4341

Volume 60

Number 2

Arch Environ Contam Toxicol (2010) 60:220-232

DOI $10.1007 /$

s00244-010-9624-0

\section{Environmental Contamination Toxicology}

Volume 60, Number 2 February 2011 
Your article is protected by copyright and all rights are held exclusively by Springer Science+Business Media, LLC. This e-offprint is for personal use only and shall not be selfarchived in electronic repositories. If you wish to self-archive your work, please use the accepted author's version for posting to your own website or your institution's repository. You may further deposit the accepted author's version on a funder's repository at a funder's request, provided it is not made publicly available until 12 months after publication. 


\title{
Effects of Ten Antibiotics on Seed Germination and Root Elongation in Three Plant Species
}

\author{
Derek G. Hillis • James Fletcher • \\ Keith R. Solomon · Paul K. Sibley
}

Received: 29 June 2010/Accepted: 25 October 2010/Published online: 24 November 2010

(C) Springer Science+Business Media, LLC 2010

\begin{abstract}
We applied a screening-level phytotoxicity assay to evaluate the effects of 10 antibiotics (at concentrations ranging from 1 to $10,000 \mu \mathrm{g} / \mathrm{L}$ ) on germination and early plant growth using three plant species: lettuce (Lactuca sativa), alfalfa (Medicago sativa), and carrot (Daucus carota). The range of phytotoxicity of the antibiotics was large, with $\mathrm{EC}_{25}$ s ranging from $3.9 \mu \mathrm{g} / \mathrm{L}$ to $>10,000 \mu \mathrm{g} / \mathrm{L}$. Chlortetracycline, levofloxacin, and sulfamethoxazole were the most phytotoxic antibiotics. $D$. $c a$ rota was the most sensitive plant species, often by an order of magnitude or more, followed by L. sativa and then M. sativa. Plant germination was insensitive to the antibiotics, with no significant decreases up to the highest treatment concentration of $10,000 \mu \mathrm{g} / \mathrm{L}$. Compared with shoot and total length measurements, root elongation was consistently the most sensitive end point. Overall, there were few instances where measured soil concentrations, if available in the publicly accessible literature, would be expected to exceed the effect concentrations of the antibiotics evaluated in this study. The use of screening assays as part of a tiered approach for evaluating environmental impacts of antibiotics can provide insight into relative species sensitivity and serve as a basis by which to screen the potential for toxic effects of novel compounds to plants.
\end{abstract}

Pharmaceuticals and personal care products (PCPPs) in the environment came to the attention of the scientific community in the late $1990 \mathrm{~s}$ (Daughton and Ternes 1999; Halling-Sørensen et al. 1998), and research relating to the

D. G. Hillis · J. Fletcher · K. R. Solomon · P. K. Sibley $(\bowtie)$

School of Environmental Sciences, Ontario Agricultural College, University of Guelph, Guelph, ON N1G 2W1, Canada

e-mail: psibley@uoguelph.ca concentrations, fate, and effects of PPCPs has increased significantly since that time. Much of this work has focused on aquatic systems. Agricultural systems are recognized as a potentially significant source of PPCPs to aquatic environments by way of runoff and leaching after the application of biosolids from wastewater treatment plants (WWTPs), manure from livestock operations, or excretion from free-ranging livestock, but the effects on agricultural soil systems have not been well documented (Thiele-Bruhn 2003; Pope et al. 2009). In terrestrial systems, research has generally focused on effects on invertebrates, particularly those associated with decomposition (Floate et al. 2005; Boxall et al. 2006; Barrett et al. 2009). Although the effects of selected PPCPs has been investigated in some terrestrial plant species (Batchelder 1982; Migliore et al. 1998, 2003), in general, our current understanding of the potential response of terrestrial plants to these compounds after exposure in soil is limited.

Exposure of plants to PPCPs in soil indicates that uptake can occur depending on the type of compound (Farkas et al. 2008; Schneider 2008). Schneider (2008) showed that sulfonamides are accumulated by plants under laboratory conditions at concentrations described as "nonnegligible" and indicated potential risks. Accumulation of sulfonamide antibiotics has also been demonstrated in aquatic plants. Tests with Lemna gibba exposed to sulfamethoxazole indicated accumulations of 0.08 and $1.2 \mu \mathrm{g} / \mathrm{g}$ plant tissue at exposures of 100 and $1000 \mu \mathrm{g} / \mathrm{L}$, respectively (Brain et al. 2008b). Kumar et al. (2005b) assessed plant uptake of tylosin and chlortetracycline in a greenhouse experiment with soil. They found that chlortetracycline was accumulated only to low ng/g levels, and tylosin was not accumulated at all. Although these studies show that uptake of some PPCPs in terrestrial plants is possible, there remains a general paucity of studies evaluating the potential for 
phytotoxic effects after exposure. A review of the literature on the effects of pharmaceuticals on aquatic macrophytes indicates the potential for phytotoxicity, particularly in the case of antibiotics that target evolutionarily conserved target sites, such as those in plastid organelles of bacterial origin common to both bacteria and plants (Brain et al. 2008a). Other toxic mechanisms may be less obvious, such as the tetracycline class of antibiotics that induces toxicity in plants directly through the chelating of metal nutrients (Nickell and Gordon 1961).

Terrestrial plant studies evaluating the toxicity of pharmaceuticals have tended to be conducted using longterm tests in soil columns; although realistic, they can be costly and labor intensive and tend to focus on single compounds and test species (Batchelder 1982; Boxall et al. 2006; Migliore et al. 1998, 2003). Formal guidelines are available for seedling emergence and vegetative vigor in soil columns by the United States Environmental Protection Agency Office of Pesticide Programs (1996a, b) and by Environment Canada (2005). It is often beneficial with novel compounds, such as PCPPs, to complete a rapid, low-cost and efficient screening test to prioritize studies requiring more intensive testing. In addition, range-finding tests are often necessary to establish concentration ranges to be used in definitive tests, such as soil column growth studies. Despite the widespread acceptance of this tiered framework, there is little research evaluating the effect of PCPPs on terrestrial organisms using standard test methods.

Germination and root elongation tests have been applied widely to terrestrial plants, although they have occasionally been criticized as being insensitive and encompassing only a single life stage (Kapustka 1997). Despite this, root elongation is often supported as a primary effect measure for plant toxicity tests because the roots are the point of contact with the exposure medium and contaminants may enter the plant through the roots (Kapustka 1997). In addition, the frequent testing of a contaminant with only a single plant species and the regular use of only a few test species of commercial importance (Wang 1992) have led to questions of ecologic relevance. We investigated the issue of interspecies sensitivity by determining the response thresholds for three plant species from three different families: carrot (Daucus carota), lettuce (Lactuca sativa), and alfalfa (Medicago sativa). D. carota has been shown to be particularly sensitive to chemical stress (Environment Canada 2005) and is both a cultivated species and a ubiquitous wild plant of temperate regions world-wide. L. sativa is considered a "standard" species due to moderate sensitivity and high frequency of use in phytotoxicological tests (ATSM 2003; Wang 1992). M. sativa is a leguminous plant that forms critical associations with nitrogen-fixing rhizobacteria, the latter having been highlighted for increased use in ecotoxicologic studies due to their indirect benefits of hosting beneficial soil bacteria (Wang 1992).

In this study, we applied a screening-level phytotoxicity assay, based on a standard toxicologic test, to (1) evaluate the relative toxicity of 10 antibiotics commonly associated with biosolids and/or manure on germination and root elongation during the early plant growth; (2) determine the relative sensitivity of the three plant species; and (3) evaluate which end points were the most sensitive indicators of phytotoxicity to the antibiotics. Six classes of antibiotics, based on mode of action, were evaluated to allow intraclass and inter-class comparisons. These included $\beta$-lactam antibiotics (amoxicillin), fluoroquinolones (levofloxacin), lincosamides (lincomycin), macrolides (tylosin), sulfonamides (sulfamethoxazole and sulfamethazine), tetracyclines (chlortetracycline, oxytetracycline, and tetracycline), and a dihydrofolate reductase inhibitor (trimethoprim).

\section{Materials and Methods}

\section{Test Species and Compounds}

Lettuce ( $L$. sativa; lot no. 7-3771), alfalfa (M. sativa; lot no. 7-5850), and carrot (D. carota; lot no. 7-6959) were purchased from the Ontario Seed Company (Waterloo, ON, Canada). Ten antibiotics were tested: amoxicillin (SigmaAldrich, St. Louis, MO; CAS no. 26787-78-0), chlortetracycline (Medisca Pharmaceutique Inc, Montreal, QC, Canada; CAS no. 64-72-2), levofloxacin (Zhejiang Pharma, Shanghai, China; CAS no. 100986-85-4), lincomycin (Sigma-Aldrich; CAS no. 859-18-7), oxytetracycline (PCCA, Houston, TX; CAS no. 2058-46-0), sulfamethazine (Sigma-Aldrich; CAS no. 57-68-1), sulfamethoxazole (Sigma-Aldrich; CAS no. 723-46-6), tetracycline (PCCA; CAS no. 64-75-5), trimethoprim (Bufa B.V. Pharmaceuticals Products, Uitgeest, The Netherlands; CAS no. 738-70-5), and tylosin (Medisca Pharmaceutique; CAS no. 74610-55-2). The purity of each tested antibiotic was at least $98 \%$.

\section{Experimental Design}

The seeds were stored at $4^{\circ} \mathrm{C}$ for at least 1 month before treatment. After the 1-month cooling period, 30 experimental units were set up according to the ASTM standard germination protocol (ATSM 2003) as follows. Ten seeds were placed onto Fisherbrand P8-creped filter article (catalog no. 09-790-12C) in $100 \times 15-\mathrm{mm}$ Fisherbrand polystyrene petri dishes (catalog no. 08-757-12). In total, five replicates containing $5-\mathrm{mL}$ aliquots of antibiotic/distilled water solutions at concentrations of $0,1,10,100,1000$, and $10,000 \mu \mathrm{g} / \mathrm{L}$ were used for each test (concentrations were 
not confirmed analytically as is often the case in [the assessment of] screening-level approaches). The $\mathrm{pH}$ of the distilled water and 10,000- $\mu \mathrm{g} / \mathrm{L}$ stock solutions was measured with an Accumet Research AR20 pH meter (Fisher Scientific). The individual experimental units for a single plant species were placed into a plastic container and blocked for container position. This container was sealed with Parafilm M (Fisher Scientific) and placed in a dark growth cabinet (model no. EF7; Conviron Controlled Environments) at $24^{\circ} \mathrm{C}$ for 5 (L. sativa and M. sativa) or for 7 days (D. carota). D. carota required more than the 5 day incubation period recommended in the standard method (ASTM International 2003) to ensure that the acceptability criterion for germination rate in the negative control exceeded $70 \%$.

\section{Boric Acid-Positive Controls}

A boric acid (Sigma-Aldrich; CAS no. 10043-35-3)-positive control was periodically tested in parallel with the antibiotic experiments at concentrations of 40, 80, 160, 320 , and $640 \mathrm{mg} / \mathrm{L}$ as defined by the method (ATSM 2003). In total, three boric acid trials were completed with each of three plant species as described previously in the experimental design; only three replicates were used per treatment. The boric acid trials were compared for consistency of threshold value estimates and response models to provide a measure of experimental variation and to ensure that the seeds responded predictably to a chemical stressor.

\section{End-Point Measurements}

At the termination of each experiment, the following end points were measured: \% germination, root length, shoot length, and total length. Percent germination was calculated as the number of seeds that germinated per dish divided by the total number of seeds per dish $\times 100$. Root length was measured from the tip of the primary root to the hypocotyl. Total length was measured from the tip of the primary root to the tip of the shoot. Both root length and total length were recorded to the nearest millimeter using a ruler. Shoot length was determined by subtracting root length from total length.

\section{Statistical Analysis}

All four end points were analyzed using "proc GLM" of SAS version 9.1.3 (SAS Institute 2003) using nominal concentrations. The end points were evaluated after 5 days for $L$. sativa and $M$. sativa or after 7 days for D. carota using one-way analysis of variance (ANOVA) to identify significant effects with a type I error rate $(\alpha)$ of 0.05 . To test the assumptions of an ANOVA, the data set was subjected to an analysis of residual error for each end point to ensure that errors were independent, homogeneous, and randomly distributed. Shapiro-Wilk's $W$ test was used to determine if the raw observations followed a normal distribution (Shapiro and Wilk 1965). If a normal distribution was not observed, then the continuous length-based end points were subjected to a natural logarithm (ln) transformation, and the quantal germination rates were subjected to an arcsine transformation. Finally, studentized residuals were calculated to test for outliers using Lund's test (Bowley 1999). When a significant effect on an end point was determined, a lowest observable effect concentration (LOEC) for that end point was computed using Dunnett's adjustment $(\alpha=0.05)$, which allows for unplanned comparisons between all means and the control.

After the performance of ANOVA, the raw data were analyzed using regression models in SigmaPlot, version 9 (Systat Software 2004). Each data set was analyzed using six reparameterized negative-response regression models for linear, exponential, logistic (three-parameter), logistic (four-parameter), Gompertz, and hormetic concentrationresponse curves, which have been previously described (Environment Canada 2005). The regression model with the highest adjusted $r^{2}$ value was selected to calculate the effective concentrations at $50 \%, 25 \%$, and $10 \%$ levels. If convergence was not obtained after applying the six regression models or if all of the models resulted in an adjusted $r^{2}<0.30$, the data set was deemed to have no concentration-response within the range tested.

\section{Quality Control}

All 30 experiments were subjected to a quality-control analysis whereby the control response for each specific pharmaceutical with a specific species was evaluated against the pooled control response values of all experiments for that species. The control response in a given experiment was considered to be atypical if it met two criteria: (1) responses of two or more end points in a given experiment were significantly different (ANOVA, $p<0.05)$ from the pooled growth measure of all the controls for a given species and (2) nonlinear regression models produced higher adjusted $r^{2}$ values using the pooled control data for the end points indicated as being atypical by the ANOVA. If the control response was deemed atypical, then the pooled control response was used to determine statistical significance using Dunnett's adjusted ANOVA and the effective concentrations using regression techniques. 


\section{Results}

Quality Control

\section{Boric Acid-Positive Controls}

Results for the boric acid positive control tests are listed in Table 1. Germination of the three plant species was unaffected by boric acid. No significant difference was detected by ANOVA in any trial, and all nonlinear regression models showed no relation.

Daucus carota was the most sensitive species: All length metrics (root, shoot, and total lengths) decreased with increasing boric acid concentrations. Effective concentrations differed little between trials, but also between end points, which is exemplified by the $\mathrm{EC}_{25} \mathrm{~s}$ for all trials and length end points, which ranged from 7.4 to $11 \mathrm{mg} / \mathrm{L}$.

Linear responses were also observed for root length and total length in $L$. sativa exposed to boric acid. The results were consistent, with $\mathrm{EC}_{25} \mathrm{~s}$ ranging from 14 to $44 \mathrm{mg} / \mathrm{L}$ for root length and from 27 to $89 \mathrm{mg} / \mathrm{L}$ for total length. However, a hormetic response was observed for shoot length, making this end point much less sensitive to boric acid, with $\mathrm{EC}_{25}$ values ranging from 213 to $272 \mathrm{mg} / \mathrm{L}$.

Medicago sativa consistently exhibited a hormetic response to boric acid for total and shoot lengths. Response thresholds were similar for both of these end points, with hormetic $\mathrm{EC}_{25} \mathrm{~s}$ ranging from 81 to $149 \mathrm{mg} / \mathrm{L}$ for total length and from 67 to $119 \mathrm{mg} / \mathrm{L}$ for shoot length. Interestingly, no effect was observed in root growth up to the highest concentration of $640 \mathrm{mg} / \mathrm{L}$.

\section{Stock Solution $\mathrm{pH}$}

The $\mathrm{pH}$ of distilled water ranged from 7.41 to 7.88 , although the $\mathrm{pH}$ values for the stock solutions were consistently lower. The largest differences in $\mathrm{pH}$ were observed for compounds purchased as a hydrochloride, such as the tetracycline class of antibiotics. None of the stock solutions had a $\mathrm{pH} \leq 5.77$, and this did not appear to be the underlying reason for phytotoxicity. The $\mathrm{pH}$ range of the boric acid stock solutions produced on different days varied from 5.77 to 6.76 , yet boric acid produced a consistent response in all three plant species. The $\mathrm{pH}$ range in the boric acid trials was similar to that of the antibiotic compounds.

\section{Control Analysis}

The average percentage germination, as well as root, shoot, and total lengths of the seedlings grown in the negative control treatments for each of the three species, are listed in
Table 2. Percent germination for each species was relatively consistent, with SDs ranging from 6.7 to 11.4; germination of plants grown in each of the negative control treatments was compared with that for the pooled data set (i.e., germination of seeds in all of the control treatments), and there were no significant differences. $D$. carota showed the greatest amount of variability in germination rate. D. carota also exhibited the greatest growth and variability in length measures during the assay duration compared with $M$. sativa and $L$. sativa. Of the 30 separate tests conducted, only plants for 4 tests were found to have length metrics that differed significantly from that for the pooled data. These included the responses of L. sativa in the control treatments for tests with chlortetracycline and levofloxacin and the responses of D. carota in the control treatment tests with sulfamethoxazole and tylosin. For these 4 tests, the data were reanalyzed using Dunnett's adjusted ANOVA and nonlinear regression of the pooled control values, and these values were used to describe the results.

\section{Experimental Results}

None of the antibiotics caused a significant decrease in seed germination for any of the three plant species (Tables 3, 4 and 5).

\section{Tetracyclines}

Of the tetracycline compounds, chlortetracycline was the most phytotoxic antibiotic to $M$. sativa, with an $\mathrm{EC}_{25}$ of $193 \mu \mathrm{g} / \mathrm{L}$; root length was significantly decreased at $100 \mu \mathrm{g} / \mathrm{L}$. For the other two species, significant decreases in root length were observed at $1000 \mu \mathrm{g} / \mathrm{L}$. The $\mathrm{EC}_{25} \mathrm{~s}$ determined for root lengths of D. carota and M. sativa were 33 and $110 \mu \mathrm{g} / \mathrm{L}$, respectively.

The response of the three plant species to oxytetracycline was highly variable, although root length was again the most sensitive end point. The relative sensitivity ranking from most to least sensitive was $D$. carota $>$ L. sativa $>$ M. sativa. Significant decreases in root lengths of $D$. carota and $L$. sativa were observed at concentrations of 1000 and $10,000 \mu \mathrm{g} / \mathrm{L}$, respectively; root length of $M$. sativa was unaffected by exposure to the highest concentration of $10,000 \mu \mathrm{g} / \mathrm{L}$. The $\mathrm{EC}_{25} \mathrm{~s}$ for the three species were 1606,4781 , and $>10,000 \mu \mathrm{g} / \mathrm{L}$ for $D$. carota, $L$. sativa, and $M$. sativa, respectively.

A negative linear response was observed for D. carota exposed to tetracycline. Significant differences in root length were observed as low as $100 \mu \mathrm{g} / \mathrm{L}$, with an $\mathrm{EC}_{25}$ of $14 \mu \mathrm{g} / \mathrm{L}$. In contrast, the other two plant species had $\mathrm{EC}_{25} \mathrm{~s}>10,000 \mu \mathrm{g} / \mathrm{L}$. 
Table 1 The effects of boric acid on germination and total, root, and shoot lengths of L. sativa (5 days), M. sativa (5 days), and D. carota (7 days) in three experimental trials ${ }^{\mathrm{a}}$

\begin{tabular}{|c|c|c|c|c|c|c|c|c|c|}
\hline Species & End point & Trial no. & $\begin{array}{l}\text { LOEC } \\
(\mathrm{mg} / \mathrm{L})\end{array}$ & $p$ & Model & $\begin{array}{l}\text { Adjusted } \\
R^{2}\end{array}$ & $\begin{array}{l}\mathrm{EC}_{50}( \pm \mathrm{SE}) \\
(\mathrm{mg} / \mathrm{L})\end{array}$ & $\begin{array}{l}\mathrm{EC}_{25}( \pm \mathrm{SE}) \\
(\mathrm{mg} / \mathrm{L})\end{array}$ & $\begin{array}{l}\mathrm{EC}_{10}( \pm \mathrm{SE}) \\
(\mathrm{mg} / \mathrm{L})\end{array}$ \\
\hline \multirow[t]{12}{*}{ Carrot (D. carota) } & \multirow[t]{3}{*}{ Germination } & 1 & NSD & 0.6346 & NR & $\mathrm{NC}$ & $>640$ & $>640$ & $>640$ \\
\hline & & 2 & NSD & 0.7650 & NR & $\mathrm{NC}$ & $>640$ & $>640$ & $>640$ \\
\hline & & 3 & NSD & 0.1911 & NR & $\mathrm{NC}$ & $>640$ & $>640$ & $>640$ \\
\hline & \multirow[t]{3}{*}{ Total length } & 1 & 160 & 0.0375 & Linear & 0.92 & $55(1.3)$ & $7.4(1.2)$ & $2.2(1.0)$ \\
\hline & & 2 & 320 & 0.0023 & Linear & 0.65 & $76(2.3)$ & $8.7(1.5)$ & $2.4(1.2)$ \\
\hline & & 3 & 160 & 0.0080 & Linear & 0.77 & $106(1.9)$ & $10(1.4)$ & $2.5(1.1)$ \\
\hline & \multirow[t]{3}{*}{ Root length } & 1 & 320 & 0.0376 & Linear & 0.98 & $38(1.1)$ & $6.2(1.1)$ & $2.1(1.0)$ \\
\hline & & 2 & 320 & 0.0376 & Linear & 0.62 & $64(2.3)$ & $8.0(1.5)$ & $2.3(1.2)$ \\
\hline & & 3 & 160 & 0.0370 & Linear & 0.94 & $112(1.4)$ & $11(1.2)$ & $2.6(1.1)$ \\
\hline & \multirow[t]{3}{*}{ Shoot length } & 1 & 160 & 0.0031 & Linear & 0.80 & $76(1.7)$ & $8.7(1.3)$ & $2.4(1.1)$ \\
\hline & & 2 & 160 & 0.0243 & Linear & 0.76 & $75(2.0)$ & $8.6(1.4)$ & $2.4(1.1)$ \\
\hline & & 3 & 160 & 0.0349 & Linear & 0.85 & $90(1.6)$ & $9.5(1.3)$ & $2.5(1.1)$ \\
\hline \multirow[t]{12}{*}{ Lettuce ( $L$. sativa) } & \multirow[t]{3}{*}{ Germination } & 1 & NSD & 0.9963 & NR & $\mathrm{NC}$ & $>640$ & $>640$ & $>640$ \\
\hline & & 2 & NSD & 0.8551 & NR & $\mathrm{NC}$ & $>640$ & $>640$ & $>640$ \\
\hline & & 3 & NSD & 0.6920 & NR & $\mathrm{NC}$ & $>640$ & $>640$ & $>640$ \\
\hline & \multirow[t]{3}{*}{ Total length } & 1 & 640 & 0.0240 & Linear & 0.61 & $>640$ & $63(2.9)$ & $5.3(1.5)$ \\
\hline & & 2 & NSD & 0.0549 & Linear & 0.71 & $>640$ & 89 (2.9) & $6.0(1.5)$ \\
\hline & & 3 & 640 & $<0.0001$ & Linear & 0.79 & $>640$ & $27(1.7)$ & $3.7(1.2)$ \\
\hline & \multirow[t]{3}{*}{ Root length } & 1 & NSD & 0.1947 & Linear & 0.65 & $>640$ & $30(2.1)$ & $3.9(1.4)$ \\
\hline & & 2 & NSD & 0.3018 & Linear & 0.56 & $>640$ & $44(3.1)$ & $4.5(1.6)$ \\
\hline & & 3 & 640 & 0.0076 & Linear & 0.85 & $180(1.8)$ & $14(1.4)$ & $2.8(1.2)$ \\
\hline & \multirow[t]{3}{*}{ Shoot length } & 1 & 640 & 0.0032 & Hormetic & 0.64 & $>640$ & $272(1.9)$ & $101(2.3)$ \\
\hline & & 2 & 640 & 0.0098 & Hormetic & 0.95 & $>640$ & $255(1.3)$ & $86(1.3)$ \\
\hline & & 3 & 640 & $<0.0001$ & Hormetic & 0.70 & $>640$ & $213(1.8)$ & $92(2.2)$ \\
\hline \multirow[t]{12}{*}{ Alfalfa (M. sativa) } & \multirow[t]{3}{*}{ Germination } & 1 & NSD & 0.9450 & NR & $\mathrm{NC}$ & $>640$ & $>640$ & $>640$ \\
\hline & & 2 & NSD & 0.7040 & NR & $\mathrm{NC}$ & $>640$ & $>640$ & $>640$ \\
\hline & & 3 & NSD & 0.9810 & NR & $\mathrm{NC}$ & $>640$ & $>640$ & $>640$ \\
\hline & \multirow[t]{3}{*}{ Total length } & 1 & 640 & 0.0007 & Linear & 0.54 & $>640$ & $281(5.8)$ & $9.5(2.0)$ \\
\hline & & 2 & 640 & 0.0239 & Hormetic & 0.98 & $>640$ & $370(1.2)$ & $149(1.2)$ \\
\hline & & 3 & 320 & 0.0062 & Hormetic & 0.74 & $>640$ & $309(1.8)$ & $81(2.1)$ \\
\hline & \multirow[t]{3}{*}{ Root length } & 1 & NSD & 0.5065 & NR & $\mathrm{NC}$ & $>640$ & $>640$ & $>640$ \\
\hline & & 2 & NSD & 0.4976 & NR & $\mathrm{NC}$ & $>640$ & $>640$ & $>640$ \\
\hline & & 3 & NSD & 0.6751 & NR & $\mathrm{NC}$ & $>640$ & $>640$ & $>640$ \\
\hline & \multirow[t]{3}{*}{ Shoot length } & 1 & 320 & 0.0359 & Hormetic & 0.56 & $>640$ & $216(2.3)$ & $70(2.9)$ \\
\hline & & 2 & 640 & 0.0049 & Hormetic & 0.82 & $>640$ & 284 (1.6) & 119 (1.6) \\
\hline & & 3 & 320 & $<0.0001$ & Hormetic & 0.90 & $>640$ & $184(1.4)$ & 67 (1.5) \\
\hline
\end{tabular}

$N C$ not calculated, $N R$ no relation determined with the nonlinear regression model at the concentration range tested, NSD no significant difference, indicating no concentration-response, Par parameter

${ }^{a}$ LOECs were calculated using ANOVA with Dunnett's adjustment for treatment-control comparisons $(\alpha=0.05)$. EC $\mathrm{x}_{\mathrm{x}}$ values are based on the nonlinear regression model with the greatest adjusted $R^{2}$

\section{Sulfonamides}

Two distinct responses were observed within the three plant species exposed to sulfamethazine. A consistent decrease in growth was observed in total, shoot, and root lengths of $D$. carota, whereas a hormetic response was observed in all three length end points for $L$. sativa and for root length in $M$. sativa. Significant decreases in $D$. carota root length were observed as low as $1000 \mu \mathrm{g} / \mathrm{L}$, whereas root growth was decreased for L. sativa and M. sativa at $10,000 \mu \mathrm{g} / \mathrm{L}$. The calculated $\mathrm{EC}_{25}$ for L. sativa, using the most sensitive measured end point (root length) was 
Table 2 Percent germination, total seedling, root, and shoot lengths (cm) of L. sativa (5 days), M. sativa (5 days), and D. carota (7 days) for plants in the negative control treatments averaged across all experimental trials $(n=10)^{\mathrm{a}}$

\begin{tabular}{lllll}
\hline Species & $\begin{array}{l}\text { Germination } \\
(\%)\end{array}$ & Total length & Root length & Shoot length \\
\hline D. carota & $76.0(11.4)$ & $42.9(16.7)$ & $19.8(11.1)$ & $23.1(6.3)$ \\
L. sativa & $90.2(9.2)$ & $25.6(7.8)$ & $11.3(4.9)$ & $14.3(3.2)$ \\
M. sativa & $94.2(6.7)$ & $38.6(6.5)$ & $13.1(3.1)$ & $25.5(4.0)$ \\
\hline
\end{tabular}

${ }^{\mathrm{a}}$ Values are means \pm SDs of the mean

$2161 \mu \mathrm{g} / \mathrm{L}$, whereas the other two plant species had $\mathrm{EC}_{25} \mathrm{~s}>10,000 \mu \mathrm{g} / \mathrm{L}$.

Sulfamethoxazole had the lowest $\mathrm{EC}_{50}$ of all the tested antibiotics at $60 \mu \mathrm{g} / \mathrm{L}$ based on D. carota root length. Significant differences in root, shoot, and total lengths were observed in D. carota at $100 \mu \mathrm{g} / \mathrm{L}$. L. sativa and M. sativa were much less sensitive to sulfamethoxazole, with an $\mathrm{EC}_{50}>10,000 \mu \mathrm{g} / \mathrm{L}$. The calculated $\mathrm{EC}_{25}$ for D. carota, using the most sensitive measured end point (total length) was $9.5 \mu \mathrm{g} / \mathrm{L}$, whereas the other two plant species had $\mathrm{EC}_{25} \mathrm{~s}>10,000 \mu \mathrm{g} / \mathrm{L}$.

\section{Other Antibiotic Classes}

Amoxicillin resulted in significant decreases only to D. carota root and total lengths. Root length was more sensitive than total length, with an $\mathrm{EC}_{25}$ of $9,342 \mu \mathrm{g} / \mathrm{L}$ compared with $9,994 \mu \mathrm{g} / \mathrm{L}$ for total length. Amoxicillin had no significant effect on either L. sativa or $M$. sativa, with corresponding $\mathrm{EC}_{25} \mathrm{~S}>10,000 \mu \mathrm{g} / \mathrm{L}$ for all end points. Root growth was found to be significantly stimulated at the lowest exposure concentration of $1 \mu \mathrm{g} / \mathrm{L}$ for $M$. sativa.

Root length was the most sensitive end point for all three of the tested species exposed to levofloxacin. L. sativa was the most sensitive species and had significantly decreased root growth at a concentration of $10 \mu \mathrm{g} / \mathrm{L}$, resulting in an $\mathrm{EC}_{25}$ of $3.9 \mu \mathrm{g} / \mathrm{L}$. A significant decrease in $M$. sativa root length was also observed at $10 \mu \mathrm{g} / \mathrm{L}$, which corresponded to an $\mathrm{EC}_{25}$ of $363 \mu \mathrm{g} / \mathrm{L}$. Levofloxacin did not cause significant decreases in $D$. carota root length, except at $10,000 \mu \mathrm{g} / \mathrm{L}$, despite the best-fit model indicating a much lower threshold of toxicity, with an $\mathrm{EC}_{25}$ of $112 \mu \mathrm{g} / \mathrm{L}$ as described by a hormetic response curve.

Daucus carota was the only plant species with any end points showing a negative response to lincomycin. Total and root lengths of $D$. carota were significantly decreased at $10,000 \mu \mathrm{g} / \mathrm{L}$, although all three length measurements resulted in EC values in the same order of magnitude of each other. Root length was again the most sensitive end point and was best described by a Gompertz nonlinear regression model, whereas total length and shoot length showed a hormetic response at concentrations $<10 \mu \mathrm{g} / \mathrm{L}$. An $\mathrm{EC}_{25}$ for the most sensitive $D$. carota end point (root length) was calculated at $1,563 \mu \mathrm{g} / \mathrm{L}$.

All three plant species were unaffected by trimethoprim, with no significant decreases measured in any end point and no concentration-response detected by any of the nonlinear regression models. Tylosin had no significant adverse effect on any end point of $L$. sativa or $M$. sativa with $\mathrm{EC}$ values $>10,000 \mu \mathrm{g} / \mathrm{L}$. A hormetic response was observed for $M$. sativa exposed to tylosin concentrations of $10 \mu \mathrm{g} / \mathrm{L}$. The root growth of $D$. carota was significantly decreased at the highest exposure concentration of $10,000 \mu \mathrm{g} / \mathrm{L}$, and the corresponding $\mathrm{EC}_{25}$ was $22 \mu \mathrm{g} / \mathrm{L}$.

\section{Discussion}

Interclass and Intraclass Differences

Comparisons of interclass and intraclass responses to antibiotics were conducted using $\mathrm{EC}_{25}$ values for the most sensitive end point (Fig. 1). Based on regression analysis, only levofloxacin produced an $\mathrm{EC}_{25}<10 \mu \mathrm{g} / \mathrm{L}$; the 4 additional compounds (chlortetracyline, tetracycline, sulfamethoxazole, and tylosin) had $\mathrm{EC}_{25} \mathrm{~s}<100 \mu \mathrm{g} / \mathrm{L}$. Interestingly, chlortetracycline was the only compound that showed a consistent phytotoxic response, with $\mathrm{EC}_{25} \mathrm{~S}$ within a single order of magnitude for all three plant species. Of the 10 tested compounds, amoxicillin and trimethoprim did not induce measureable phytotoxic effects on any plant species based on $\mathrm{EC}_{25} \mathrm{~s}$. Trimethoprim was the only antibiotic not to produce a significant lowest observable adverse effect level in any species up to the maximum concentration tested of $10,000 \mu \mathrm{g} / \mathrm{L}$. Ranking of the geometric mean of $\mathrm{EC}_{25} \mathrm{~s}$ for the most sensitive end point for the three species to a given antibiotic indicated an order of most to least phytotoxic of levofloxacin $>$ chlortetracycline $>$ tetracycline $>$ sulfamethoxazole $>$ tylosin $>$ oxytetracycline $>$ sulfamethazine $>$ lincomycin $>$ amoxicillin $>$ trimethoprim. As a whole, the range of phytotoxicity of the antibiotics was large, with $\mathrm{EC}_{25} \mathrm{~S}$ ranging from 3.9 to $>10,000 \mu \mathrm{g} / \mathrm{L}$.

With few exceptions, intraclass differences in potency were relatively small. Among the tetracyclines, within a plant species, potency was moderate, and phytotoxic responses to chlortetracycline and tetracycline were typically within an order of magnitude of each other. In contrast, oxytetracycline was considerably less potent than the other tetracyclines, with a response threshold typically two orders of magnitude greater than that calculated for chlortetracycline or tetracycline. For example, the $\mathrm{EC}_{10}$ for chlortetracycline and tetracycline to $M$. sativa was 7.2 and $71 \mu \mathrm{g} / \mathrm{L}$, respectively, whereas the $\mathrm{EC}_{10}$ for 
Table 3 The effects of 10 antibiotics on germination and growth of D. carota exposed for 7 days ${ }^{\mathrm{a}}$

\begin{tabular}{|c|c|c|c|c|c|c|c|c|}
\hline Compound & End point & $\begin{array}{l}\mathrm{LOEC} \\
(\mu \mathrm{g} / \mathrm{L})\end{array}$ & $p$ & Model & Adjusted $R^{2}$ & $\begin{array}{l}\mathrm{EC}_{50}( \pm \mathrm{SE}) \\
(\mu \mathrm{g} / \mathrm{L})\end{array}$ & $\begin{array}{l}\mathrm{EC}_{25}( \pm \mathrm{SE}) \\
(\mu \mathrm{g} / \mathrm{L})\end{array}$ & $\begin{array}{l}\mathrm{EC}_{10}( \pm \mathrm{SE}) \\
(\mu \mathrm{g} / \mathrm{L})\end{array}$ \\
\hline \multicolumn{9}{|l|}{ Tetracyclines } \\
\hline \multirow[t]{4}{*}{ Chlortetracycline } & Germination & NSD & 0.9966 & NR & $\mathrm{NC}$ & $>10,000$ & $>10,000$ & $>10,000$ \\
\hline & Total length & 10,000 & 0.0005 & Gompertz & 0.94 & $6212(0.2)$ & $915(0.7)$ & $170(1.2)$ \\
\hline & Root length & 1000 & 0.0230 & Linear & 0.99 & $1141(0.3)$ & $33(0.1)$ & $3.1(0.1)$ \\
\hline & Shoot length & 10,000 & 0.0023 & Gompertz & 0.92 & $7479(0.4)$ & $1705(0.7)$ & $424(1.2)$ \\
\hline \multirow[t]{4}{*}{ Oxytetracycline } & Germination & NSD & 0.3115 & NR & $\mathrm{NC}$ & $>10,000$ & $>10,000$ & $>10,000$ \\
\hline & Total length & 1000 & 0.0343 & Gompertz & 0.85 & $5626(0.5)$ & $2053(1.0)$ & $749(1.8)$ \\
\hline & Root length & 1000 & $<0.0001$ & Gompertz & 0.74 & $4909(0.8)$ & $1606(1.7)$ & $536(3.1)$ \\
\hline & Shoot length & 10,000 & $<0.0001$ & Gompertz & 0.88 & $6563(0.4)$ & $2872(0.9)$ & $1229(1.7)$ \\
\hline \multirow[t]{4}{*}{ Tetracycline } & Germination & NSD & 0.7721 & NR & $\mathrm{NC}$ & $>10,000$ & $>10,000$ & $>10,000$ \\
\hline & Total length & 100 & 0.0081 & Linear & 0.90 & $677(1.0)$ & $25(0.4)$ & $2.7(0.1)$ \\
\hline & Root length & 100 & 0.0181 & Linear & 0.93 & $212(0.6)$ & $14(0.3)$ & $1.9(0.1)$ \\
\hline & Shoot length & 1000 & 0.0477 & Linear & 0.80 & $2499(2.8)$ & $49(1.0)$ & $3.8(0.3)$ \\
\hline \multicolumn{9}{|l|}{ Sulfonamides } \\
\hline \multirow[t]{4}{*}{ Sulfamethazine } & Germination & NSD & 0.7236 & NR & $\mathrm{NC}$ & $>10,000$ & $>10,000$ & $>10,000$ \\
\hline & Total length & 1000 & 0.0474 & Linear & 0.63 & $>10,000$ & $>10,000$ & $85(2.7)$ \\
\hline & Root length & 1000 & 0.0093 & Linear & 0.58 & $>10,000$ & $>10,000$ & $65(2.9)$ \\
\hline & Shoot length & NSD & 0.0982 & Linear & 0.48 & $>10,000$ & $>10,000$ & $120(5.3)$ \\
\hline \multirow[t]{4}{*}{ Sulfamethoxazole } & Germination & NSD & 1.0000 & NR & $\mathrm{NC}$ & $>10,000$ & $>10,000$ & $>10,000$ \\
\hline & Total length $^{\mathrm{b}}$ & 100 & 0.0240 & $\log (3-\mathrm{Par})$ & 0.90 & $590(2.9)$ & $9.5(1.7)$ & $1.4(0.9)$ \\
\hline & Root length $^{\mathrm{b}}$ & 100 & 0.0353 & $\log (4-P a r)$ & 0.92 & $60(0.9)$ & $19(0.9)$ & $11(1.2)$ \\
\hline & Shoot length ${ }^{\mathrm{b}}$ & 100 & 0.0356 & $\log (3-\mathrm{Par})$ & 0.87 & $>10,000$ & $88(3.2)$ & $3.5(1.8)$ \\
\hline \multicolumn{9}{|c|}{ Other antibiotic classes } \\
\hline \multirow[t]{4}{*}{ Amoxicillin } & Germination & NSD & 0.9976 & NR & $\mathrm{NC}$ & $>10,000$ & $>10,000$ & $>10,000$ \\
\hline & Total length & 10,000 & 0.0428 & Gompertz & 0.51 & $>10,000$ & $9994(4.5)$ & $8382(1681)$ \\
\hline & Root length & 10,000 & 0.0009 & Gompertz & 0.73 & $>10,000$ & $9342(22)$ & $5494(58)$ \\
\hline & Shoot length & NSD & 0.5979 & NR & $\mathrm{NC}$ & $>10,000$ & $>10,000$ & $>10,000$ \\
\hline \multirow[t]{4}{*}{ Levofloxacin } & Germination & NSD & 0.6201 & NR & $\mathrm{NC}$ & $>10,000$ & $>10,000$ & $>10,000$ \\
\hline & Total length & 10,000 & 0.0044 & Hormetic & 0.43 & $6050(32)$ & $814(6.6)$ & $351(4.8)$ \\
\hline & Root length & 10,000 & 0.0003 & Hormetic & 0.49 & 218 (3.6) & $112(2.0)$ & $83(2.0)$ \\
\hline & Shoot length & 10,000 & 0.0011 & $\log (3-P a r)$ & 0.45 & $8866(5.5)$ & $989(6.4)$ & $188(17)$ \\
\hline \multirow[t]{4}{*}{ Lincomycin } & Germination & NSD & 0.9995 & NR & $\mathrm{NC}$ & $>10,000$ & $>10,000$ & $>10,000$ \\
\hline & Total length & 10,000 & 0.0006 & Hormetic & 0.96 & $>10,000$ & $2671(0.6)$ & $319(0.7)$ \\
\hline & Root length & 10,000 & $<0.0001$ & Gompertz & 0.96 & $>10,000$ & $1563(0.5)$ & $233(0.9)$ \\
\hline & Shoot length & NSD & 0.0524 & Hormetic & 0.96 & $>10,000$ & $7356(0.8)$ & $542(0.7)$ \\
\hline \multirow[t]{4}{*}{ Trimethoprimum } & Germination & NSD & 0.9852 & NR & $\mathrm{NC}$ & $>10,000$ & $>10,000$ & $>10,000$ \\
\hline & Total length & NSD & 0.5434 & NR & $\mathrm{NC}$ & $>10,000$ & $>10,000$ & $>10,000$ \\
\hline & Root length & NSD & 0.4039 & NR & $\mathrm{NC}$ & $>10,000$ & $>10,000$ & $>10,000$ \\
\hline & Shoot length & NSD & 0.8631 & NR & $\mathrm{NC}$ & $>10,000$ & $>10,000$ & $>10,000$ \\
\hline \multirow[t]{4}{*}{ Tylosin } & Germination & NSD & 1.0000 & NR & $\mathrm{NC}$ & $>10,000$ & $>10,000$ & $>10,000$ \\
\hline & Total length $^{\mathrm{b}}$ & 10,000 & 0.0137 & Linear & 0.71 & $>10,000$ & $232(2.5)$ & $7.8(0.7)$ \\
\hline & Root length $^{\mathrm{b}}$ & 10,000 & 0.0074 & Linear & 0.82 & $542(1.5)$ & $22(0.6)$ & $2.5(0.2)$ \\
\hline & Shoot length & NSD & 0.9131 & NR & $\mathrm{NC}$ & $>10,000$ & $>10,000$ & $>10,000$ \\
\hline
\end{tabular}

NC not calculated, $N R$ no relation determined with the nonlinear regression model at the concentration range tested, NSD no significant difference, Par parameter

${ }^{a}$ LOECs were calculated using ANOVA with Dunnett's adjustment for treatment-control comparisons $(\alpha=0.05)$. $\mathrm{EC}_{\mathrm{x}}$ values are based on the nonlinear regression model with the greatest adjusted $R^{2}$

b Treatments were evaluated compared with a pooled control response 
Table 4 The effects of 10 antibiotics on germination and growth of $L$. sativa exposed for 5 days ${ }^{\mathrm{a}}$

\begin{tabular}{|c|c|c|c|c|c|c|c|c|}
\hline Compound & End point & $\begin{array}{l}\mathrm{LOEC} \\
(\mu \mathrm{g} / \mathrm{L})\end{array}$ & $p$ & Model & Adjusted $R^{2}$ & $\begin{array}{l}\mathrm{EC}_{50}( \pm \mathrm{SE}) \\
(\mu \mathrm{g} / \mathrm{L})\end{array}$ & $\begin{array}{l}\mathrm{EC}_{25}( \pm \mathrm{SE}) \\
(\mu \mathrm{g} / \mathrm{L})\end{array}$ & $\begin{array}{l}\mathrm{EC}_{10}( \pm \mathrm{SE}) \\
(\mu \mathrm{g} / \mathrm{L})\end{array}$ \\
\hline \multicolumn{9}{|l|}{ Tetracyclines } \\
\hline \multirow[t]{4}{*}{ Chlortetracycline } & Germination & NSD & 0.7743 & Gompertz & 0.40 & $>10,000$ & $>10,000$ & $>10,000$ \\
\hline & Total length $^{\mathrm{b}}$ & 1000 & 0.0196 & Linear & 0.53 & $>10,000$ & $5629(19)$ & $30.6(2.3)$ \\
\hline & Root length $^{\mathrm{b}}$ & 1000 & 0.0195 & Linear & 0.55 & $>10,000$ & $110(3.2)$ & $5.6(0.8)$ \\
\hline & Shoot length & NSD & 0.4719 & NR & $\mathrm{NC}$ & $>10,000$ & $>10,000$ & $>10,000$ \\
\hline \multirow[t]{4}{*}{ Oxytetracycline } & Germination & NSD & 0.2015 & NR & $\mathrm{NC}$ & $>10,000$ & $>10,000$ & $>10,000$ \\
\hline & Total length & 10,000 & 0.0073 & Gompertz & 0.90 & $>10,000$ & $7315(0.3)$ & $1687(0.9)$ \\
\hline & Root length & 10,000 & 0.0002 & Gompertz & 0.91 & $>10,000$ & $4781(0.5)$ & $1815(1.2)$ \\
\hline & Shoot length & NSD & 0.3031 & Gompertz & 0.85 & $>10,000$ & $>10,000$ & $2402(1.0)$ \\
\hline \multirow[t]{4}{*}{ Tetracycline } & Germination & NSD & 0.9929 & NR & $\mathrm{NC}$ & $>10,000$ & $>10,000$ & $>10,000$ \\
\hline & Total length & NSD & 0.1906 & Gompertz & 0.32 & $>10,000$ & $>10,000$ & $2654(4.8)$ \\
\hline & Root length & NSD & 0.1747 & Gompertz & 0.78 & $>10,000$ & $>10,000$ & $1433(1.9)$ \\
\hline & Shoot length & NSD & 0.4806 & NR & $\mathrm{NC}$ & $>10,000$ & $>10,000$ & $>10,000$ \\
\hline \multicolumn{9}{|l|}{ Sulfonamides } \\
\hline \multirow[t]{4}{*}{ Sulfamethazine } & Germination & NSD & 1.0000 & NR & $\mathrm{NC}$ & $>10,000$ & $>10,000$ & $>10,000$ \\
\hline & Total length & 10,000 & 0.0032 & Hormetic & 0.84 & $>10,000$ & $6470(0.9)$ & $1658(0.8)$ \\
\hline & Root length & 10,000 & $<0.0001$ & Hormetic & 0.84 & $>10,000$ & $2161(0.7)$ & $851(1.0)$ \\
\hline & Shoot length & NSD & 0.4068 & Hormetic & 0.79 & $>10,000$ & $>10,000$ & $9128(1.2)$ \\
\hline \multirow[t]{4}{*}{ Sulfamethoxazole } & Germination & NSD & 0.3825 & NR & $\mathrm{NC}$ & $>10,000$ & $>10,000$ & $>10,000$ \\
\hline & Total length & NSD & 0.3387 & Gompertz & 0.67 & $>10,000$ & $>10,000$ & $4398(1.3)$ \\
\hline & Root length & 10,000 & 0.0346 & Gompertz & 0.36 & $>10,000$ & $>10,000$ & $1367(7.7)$ \\
\hline & Shoot length & NSD & 0.9999 & Hormetic & 0.84 & $>10,000$ & $>10,000$ & $>10,000$ \\
\hline \multicolumn{9}{|c|}{ Other antibiotic classes } \\
\hline \multirow[t]{4}{*}{ Amoxicillin } & Germination & NSD & 0.7871 & Log (3-Par) & 0.32 & $>10,000$ & $>10,000$ & $>10,000$ \\
\hline & Total length & NSD & 0.9917 & NR & $\mathrm{NC}$ & $>10,000$ & $>10,000$ & $>10,000$ \\
\hline & Root length & $1^{\mathrm{a}}$ & 0.0415 & NR & $\mathrm{NC}$ & $>10,000$ & $>10,000$ & $>10,000$ \\
\hline & Shoot length & NSD & 0.9999 & NR & $\mathrm{NC}$ & $>10,000$ & $>10,000$ & $>10,000$ \\
\hline \multirow[t]{4}{*}{ Levofloxacin } & Germination & NSD & 0.8538 & Hormetic & 0.54 & $>10,000$ & $>10,000$ & $>10,000$ \\
\hline & Total length $^{\mathrm{b}}$ & 100 & 0.0211 & Linear & 0.40 & $>10,000$ & 2864 (28) & $23.1(2.8)$ \\
\hline & Root length $^{\mathrm{b}}$ & 10 & 0.0037 & Log (3-Par) & 0.45 & 113 (17) & $3.9(5.6)$ & $0.7(1.8)$ \\
\hline & Shoot length $^{\mathrm{b}}$ & NSD & 0.4682 & Linear & 0.53 & $>10,000$ & $>10,000$ & $938(11.3)$ \\
\hline \multirow[t]{4}{*}{ Lincomycin } & Germination & NSD & 0.9149 & NR & $\mathrm{NC}$ & $>10,000$ & $>10,000$ & $>10,000$ \\
\hline & Total length & NSD & 0.9812 & NR & $\mathrm{NC}$ & $>10,000$ & $>10,000$ & $>10,000$ \\
\hline & Root length & NSD & 0.3958 & NR & $\mathrm{NC}$ & $>10,000$ & $>10,000$ & $>10,000$ \\
\hline & Shoot length & NSD & 0.7692 & NR & $\mathrm{NC}$ & $>10,000$ & $>10,000$ & $>10,000$ \\
\hline \multirow[t]{4}{*}{ Trimethoprimum } & Germination & NSD & 0.9992 & NR & $\mathrm{NC}$ & $>10,000$ & $>10,000$ & $>10,000$ \\
\hline & Total Length & NSD & 0.9968 & NR & $\mathrm{NC}$ & $>10,000$ & $>10,000$ & $>10,000$ \\
\hline & Root length & NSD & 1.0000 & NR & $\mathrm{NC}$ & $>10,000$ & $>10,000$ & $>10,000$ \\
\hline & Shoot length & NSD & 0.9565 & NR & $\mathrm{NC}$ & $>10,000$ & $>10,000$ & $>10,000$ \\
\hline \multirow[t]{4}{*}{ Tylosin } & Germination & NSD & 1.0000 & NR & $\mathrm{NC}$ & $>10,000$ & $>10,000$ & $>10,000$ \\
\hline & Total length & 1000 & 0.0135 & NR & $\mathrm{NC}$ & $>10,000$ & $>10,000$ & $>10,000$ \\
\hline & Root length & 10,000 & 0.0412 & NR & $\mathrm{NC}$ & $>10,000$ & $>10,000$ & $>10,000$ \\
\hline & Shoot length & NSD & 0.4028 & NR & $\mathrm{NC}$ & $>10,000$ & $>10,000$ & $>10,000$ \\
\hline
\end{tabular}

$N C$ not calculated, $N R$ no relation determined with the nonlinear regression model at the concentration range tested, NSD no significant difference; $P a r=$ parameter

${ }^{a}$ LOECs were calculated using ANOVA with Dunnett's adjustment for treatment-control comparisons $(\alpha=0.05)$. EC $\mathrm{x}_{\mathrm{x}}$ values are based on the nonlinear regression model with the greatest adjusted $R^{2}$

b Treatments were evaluated compared with a pooled control response 
Table 5 The effects of 10 antibiotics on germination and growth of $M$. sativa exposed for 5 days ${ }^{\mathrm{a}}$

\begin{tabular}{|c|c|c|c|c|c|c|c|c|}
\hline Compound & End point & $\begin{array}{l}\mathrm{LOEC} \\
(\mu \mathrm{g} / \mathrm{L})\end{array}$ & $p$ & Model & Adjusted $R^{2}$ & $\begin{array}{l}\mathrm{EC}^{50}( \pm \mathrm{SE}) \\
(\mu \mathrm{g} / \mathrm{L})\end{array}$ & $\begin{array}{l}\mathrm{EC}_{25}( \pm \mathrm{SE}) \\
(\mu \mathrm{g} / \mathrm{L})\end{array}$ & $\begin{array}{l}\mathrm{EC}_{10}( \pm \mathrm{SE}) \\
(\mu \mathrm{g} / \mathrm{L})\end{array}$ \\
\hline \multicolumn{9}{|l|}{ Tetracyclines } \\
\hline \multirow[t]{4}{*}{ Chlortetracycline } & Germination & NSD & 0.9113 & NR & $\mathrm{NC}$ & $>10,000$ & $>10,000$ & $>10,000$ \\
\hline & Total length & 10,000 & 0.0176 & Linear & 0.59 & $>10,000$ & $>10,000$ & $171(4.3)$ \\
\hline & Root length & 100 & $<0.0001$ & Linear & 0.92 & $>10,000$ & $193(0.8)$ & $7.2(0.3)$ \\
\hline & Shoot length & NSD & 0.7752 & NR & $\mathrm{NC}$ & $>10,000$ & $>10,000$ & $>10,000$ \\
\hline \multirow[t]{4}{*}{ Oxytetracycline } & Germination & NSD & 0.9396 & NR & $\mathrm{NC}$ & $>10,000$ & $>10,000$ & $>10,000$ \\
\hline & Total length & NSD & 0.6679 & NR & $\mathrm{NC}$ & $>10,000$ & $>10,000$ & $>10,000$ \\
\hline & Root length & NSD & 0.5016 & Hormetic & 0.64 & $>10,000$ & $>10,000$ & $6730(1.3)$ \\
\hline & Shoot length & NSD & 0.8548 & NR & $\mathrm{NC}$ & $>10,000$ & $>10,000$ & $>10,000$ \\
\hline \multirow[t]{4}{*}{ Tetracycline } & Germination & NSD & 0.4406 & NR & $\mathrm{NC}$ & $>10,000$ & $>10,000$ & $>10,000$ \\
\hline & Total length & NSD & 0.1188 & Gompertz & 0.90 & $>10,000$ & $>10,000$ & $880(1.4)$ \\
\hline & Root length & NSD & 0.0787 & Linear & 0.83 & $>10,000$ & $>10,000$ & $71(1.2)$ \\
\hline & Shoot length & NSD & 0.2882 & Log (3-Par) & 0.85 & $>10,000$ & $>10,000$ & $2603(0.9)$ \\
\hline \multicolumn{9}{|l|}{ Sulfonamides } \\
\hline \multirow[t]{4}{*}{ Sulfamethazine } & Germination & NSD & 0.9982 & NR & $\mathrm{NC}$ & $>10,000$ & $>10,000$ & $>10,000$ \\
\hline & Total length & NSD & 0.2993 & NR & $\mathrm{NC}$ & $>10,000$ & $>10,000$ & $>10,000$ \\
\hline & Root length & 10,000 & 0.0129 & Hormetic & 0.44 & $>10,000$ & $>10,000$ & $5336(1.3)$ \\
\hline & Shoot length & NSD & 0.8911 & NR & $\mathrm{NC}$ & $>10,000$ & $>10,000$ & $>10,000$ \\
\hline \multirow[t]{4}{*}{ Sulfamethoxazole } & Germination & NSD & 0.6853 & NR & $\mathrm{NC}$ & $>10,000$ & $>10,000$ & $>10,000$ \\
\hline & Total length & NSD & 0.8916 & NR & $\mathrm{NC}$ & $>10,000$ & $>10,000$ & $>10,000$ \\
\hline & Root length & NSD & 0.8485 & NR & $\mathrm{NC}$ & $>10,000$ & $>10,000$ & $>10,000$ \\
\hline & Shoot length & NSD & 0.9421 & NR & $\mathrm{NC}$ & $>10,000$ & $>10,000$ & $>10,000$ \\
\hline \multicolumn{9}{|c|}{ Other antibiotic classes } \\
\hline \multirow[t]{4}{*}{ Amoxicillin } & Germination & NSD & 0.9539 & NR & $\mathrm{NC}$ & $>10,000$ & $>10,000$ & $>10,000$ \\
\hline & Total length & NSD & 0.7592 & NR & $\mathrm{NC}$ & $>10,000$ & $>10,000$ & $>10,000$ \\
\hline & Root length & $1^{\mathrm{b}}$ & 0.0325 & NR & $\mathrm{NC}$ & $>10,000$ & $>10,000$ & $>10,000$ \\
\hline & Shoot length & NSD & 0.7915 & NR & $\mathrm{NC}$ & $>10,000$ & $>10,000$ & $>10,000$ \\
\hline \multirow[t]{4}{*}{ Levofloxacin } & Germination & $1^{\mathrm{b}}$ & 0.0145 & NR & $\mathrm{NC}$ & $>10,000$ & $>10,000$ & $>10,000$ \\
\hline & Total length & 100 & 0.0223 & Linear & 0.51 & $>10,000$ & $>10,000$ & $87(4.1)$ \\
\hline & Root length & 10 & 0.0092 & Linear & 0.55 & $>10,000$ & $363(5.5)$ & $9.6(1.1)$ \\
\hline & Shoot length & NSD & 0.1199 & Linear & 0.31 & $>10,000$ & $>10,000$ & $2280(58)$ \\
\hline \multirow[t]{4}{*}{ Lincomycin } & Germination & NSD & 0.6870 & NR & $\mathrm{NC}$ & $>10,000$ & $>10,000$ & $>10,000$ \\
\hline & Total length & NSD & 0.5461 & NR & $\mathrm{NC}$ & $>10,000$ & $>10,000$ & $>10,000$ \\
\hline & Root length & NSD & 0.9137 & NR & $\mathrm{NC}$ & $>10,000$ & $>10,000$ & $>10,000$ \\
\hline & Shoot length & NSD & 0.1266 & NR & $\mathrm{NC}$ & $>10,000$ & $>10,000$ & $>10,000$ \\
\hline \multirow[t]{4}{*}{ Trimethoprimum } & Germination & NSD & 0.9963 & NR & $\mathrm{NC}$ & $>10,000$ & $>10,000$ & $>10,000$ \\
\hline & Total length & NSD & 0.6030 & NR & $\mathrm{NC}$ & $>10,000$ & $>10,000$ & $>10,000$ \\
\hline & Root length & NSD & 0.9643 & NR & $\mathrm{NC}$ & $>10,000$ & $>10,000$ & $>10,000$ \\
\hline & Shoot length & NSD & 0.2981 & NR & $\mathrm{NC}$ & $>10,000$ & $>10,000$ & $>10,000$ \\
\hline \multirow[t]{4}{*}{ Tylosin } & Germination & NSD & 0.9673 & Gompertz & $\mathrm{NC}$ & $>10,000$ & $>10,000$ & $>10,000$ \\
\hline & Total length & NSD & 0.9553 & NR & $\mathrm{NC}$ & $>10,000$ & $>10,000$ & $>10,000$ \\
\hline & Root length & $10^{\mathrm{b}}$ & 0.0231 & Hormetic & $\mathrm{NC}$ & $>10,000$ & $>10,000$ & $>10,000$ \\
\hline & Shoot length & NSD & 0.9974 & NR & $\mathrm{NC}$ & $>10,000$ & $>10,000$ & $>10,000$ \\
\hline
\end{tabular}

NC not calculated, $N R$ no relation determined with the nonlinear regression model at the concentration range tested, NSD no significant difference, Par parameter

${ }^{a}$ LOECs were calculated using ANOVA with Dunnett's adjustment for treatment-control comparisons $(\alpha=0.05)$. $\mathrm{EC}_{\mathrm{x}}$ values are based on the nonlinear regression model with the greatest adjusted $R^{2}$

b The end point showed a significant dose-response increase from the control 


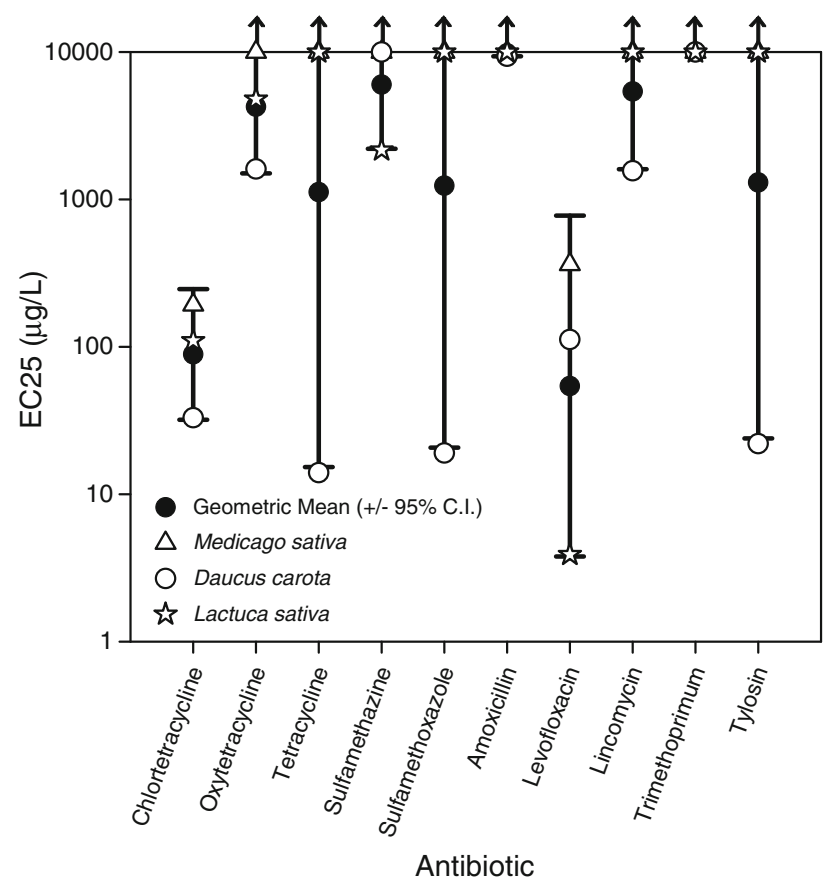

Fig. 1 The $E_{25} \mathrm{~S}$ and geometric mean of the $\mathrm{EC}_{25}( \pm 95 \%$ confidence intervals) of 3 plant species (D. carota, $L$. sativa, and $M$. sativa) exposed to 10 different antibiotic compounds for 5 days (L. sativa, M. sativa) or for 7 days (D. carota). The $\mathrm{EC}_{25}$ of the most sensitive end point measured (germination, root length, shoot length, or total length) for a given species is presented

oxytetracycline was $6,730 \mu \mathrm{g} / \mathrm{L}$. Similar trends have been found in aquatic plants exposed to tetracyclines (Brain et al. 2008a). Among the sulfonamides, sulfamethoxazole and sulfamethazine typically exhibited potency differences less than one order of magnitude within a plant species. In rankings of phytotoxicity, the sulfonamides were fourth and fifth for D. carota, with root length $\mathrm{EC}_{10} \mathrm{~s}$ of 11 and $65 \mu \mathrm{g} / \mathrm{L}$, and third and fourth for L. sativa, with root length $\mathrm{EC}_{10} \mathrm{~s}$ of 851 and $1,367 \mu \mathrm{g} / \mathrm{L}$. The relative similarity in threshold values for a given class of pharmaceutical is to be expected because these compounds, despite structural differences, behave similarly and elicited similar responses in the three species tested.

\section{Interspecies Extrapolation}

In general, $D$. carota was the most sensitive species to antibiotics, followed by $L$. sativa, with the most tolerant species being $M$. sativa, although isolated exceptions were observed (Fig. 1). Interspecies differences for phytotoxicological responses to a given chemical stressor are often one or two orders of magnitude for both inorganic and organic compounds (Wang 1992). The range of tolerance to antibiotics in this study typically fell within this range. For sulfamethoxazole and tetracycline, interspecies differences in sensitivity varied by up to three orders of magnitude. The wide range of response to antibiotics among species supports the need for testing environmental contaminants on a battery of different plant species and suggests that interspecies extrapolation between plants should be applied carefully (Kapustka 1997).

Although application of the ASTM standard method (ASTM International 2003) was successful in most cases, we encountered problems with the use of this test with $D$. carota, which required changes to the method. For example, $D$. carota required a 7 -day (168-h) assay length instead of the recommended 5-day (120-h) duration to ensure that germination met the prescribed acceptability criteria for the control and to provide reliable and consistent length measurements. The method stipulates that a minimum of $80 \%$ of the negative control seeds must have germinated for the test to be valid (ASTM International 2003). This standard was easily met with $L$. sativa and $M$. sativa but not with $D$. carota, which had a germination rate of $<50 \%$ at 5 days and $76 \%$ at 7 days. Other standard phytotoxicity methods have noted lower germination percentages associated with D. carota (Environment Canada 2005) and therefore stipulate a lower acceptable $\%$ germination of $60 \%$. The slightly longer exposure time needed to obtain consistent growth measures and germination rates in $D$. carota may in part be responsible for this species being the most sensitive.

Another contributing factor to the measured differences in toxicity between plant species exposed to a contaminant may be the development of nonlinear models better equipped to deal with typical plant responses. Threshold values for all three species were often best fit by hormetic and Gompertz models introduced by Stephenson et al. (2000) for plant toxicity tests and subsequently adopted by some regulatory agencies (Environment Canada 2005) as standard practice for the analysis of nonquantal phytotoxicity data. These two models were only recently incorporated into the suite of typical phytotoxic responses along with the more common linear, exponential and log (threeor four- parameter) models. The root, shoot, and total length responses to the tested antibiotics supports the inclusion of hormetic and Gompertz curves as a common approach for measuring phytotoxic response when exposed to a chemical stressor.

\section{Germination and Root Elongation} as Relevant End Points

The results of this study suggest that germination is not a useful end point for plant testing. No significant effects on germination were observed for any of the 10 antibiotics up to the highest treatment concentration of $10,000 \mu \mathrm{g} / \mathrm{L}$. Fundamentally, this confirms that plant germination is a highly conserved process, with many of the nutrients, carbohydrates, and proteins stored and available for 
seedling emergence even if cellular processes to convert these compounds to more bioavailable forms are negatively affected. For example, the sulfonamide class of pharmaceuticals inhibits plant folate synthesis in a mechanism similar to that which causes its antibacterial activity (Basset et al. 2002, 2005). Folates are essential cofactors in one-carbon transfer reactions for all organisms. Initial concentrations of folate in seeds have been shown to support root elongation during the initial growth period (Gambonnet et al. 2001) indicating that, where specific mechanisms of effect are known to occur after initial seed germination and radical growth, longer-duration plantbased experiments should be conducted to evaluate effects. Both of the sulfonamides evaluated, sulfamethoxazole and sulfamethazine, did not elicit effects on seed germination in the three species. In contrast, effects on root elongation were observed for these compounds, and these measures would have triggered further investigation. The increased sensitivity of root growth compared with germination to phytotoxic compounds is a common observation in plant studies. Germination and root elongation experiments on Cucumbis sativa using 13-halogen substituted phenols showed that root elongation produced lower $\mathrm{EC}_{50}$ values for all but two of the tested compounds compared with germination (Wang et al. 2001).

With few exceptions, root elongation was the most sensitive end point of the three length measurements for each of the plant species. Compared with germination, root elongation detected antibiotic-induced phytotoxic responses regularly, with all compounds eliciting $\mathrm{EC}_{25}$ values $<10,000 \mu \mathrm{g} / \mathrm{L}$ in $D$. carota, except trimethoprim and sulfamethazine. This result supports the continued use of root elongation as the primary end point in conducting shortduration culture experiments (Kapustka 1997). One exception was considered important: The most sensitive end point in the positive control boric acid-exposed $M$. sativa was shoot length, which indicates that the additional measurements of total or shoot lengths may in some situations be warranted.

\section{Risk Assessment}

The determination of toxicity of antibiotics to plants provides a good example of why the application of a tiered risk assessment is beneficial. For example, in this study, chlortetracycline was determined to be one of the more toxic compounds at environmentally relevant concentrations, with significant effects observed as low as $1,000 \mu \mathrm{g} / \mathrm{L}$ and $\mathrm{EC}_{25}$ s ranging from 33 to $193 \mu \mathrm{g} / \mathrm{L}$. Environmental concentrations of chlortetracycline as high as $7,730 \mu \mathrm{g} / \mathrm{L}$ have been observed in swine manure (Kumar et al. 2005a), which indicates the need for further testing. However, when corn plants were evaluated using a soil-column protocol with chlortetracycline concentrations $\leq 160,000 \mu \mathrm{g} / \mathrm{kg}$, effects were not observed (Batchelder 1982). The difference in effects is likely a function of bioavailability in soil compared with the water solution used in germination trials. An analogous compound, tetracycline, has a reported $K_{\mathrm{d}}$ of $8,400 \mathrm{~kg} \mathrm{~L}^{-1}$, suggesting that it will adsorb strongly to soil particulate matter (Sithole and Guy 1987a, b). Adsorption of chlortetracycline to soil particles would result in low porewater concentrations and a decrease in the chlortetracycline available for uptake to plant roots.

Another important consideration in assessing the risk of antibiotics to the environment is the specific use of the antibiotic, such as whether it is primarily used in human or veterinary treatment as well as whether exposures result from low-level prophylactic uses or a large pulse after a disease outbreak. Of importance in an agricultural context is how biosolids or manures containing pharmaceuticals are stored and treated before they are applied to a terrestrial system. This is exemplified by the sulfonamides. Grab samples collected from soils of Swiss farms showed total active sulfonamide concentrations of $\leq 20,000 \mu \mathrm{g} / \mathrm{kg}$ (Haller et al. 2002). Individually, sulfamethazine concentrations were measured as high as $8,700 \mu \mathrm{g} / \mathrm{kg}$. These concentrations were within the range of $\mathrm{EC}_{25} \mathrm{~s}$ calculated in this study for $D$. carota and $L$. sativa. In human treatment, sulfonamides would typically be processed by a WWTP before application to land in the form of WWTP biosolids. Concentrations of sulfonamides in sludge have been shown to be greatly decreased after anaerobic digestion, commonly used on waste activated sludge. Göbel et al. (2005) found that anaerobic digestion decreased sulfamethoxazole concentrations in sludge from $68 \mathrm{mg} / \mathrm{kg}$ to nondetectable levels and sulfapyridine from $28 \mathrm{mg} / \mathrm{kg}$ to $1 \mathrm{mg} / \mathrm{kg}$ in Swiss WWTPs. For plants, anaerobic digestion of animal manure in holding tanks before application onto agricultural fields might decrease the risk associated with sulfonamide toxicity from land application of manure.

\section{Conclusion}

We assessed the toxicity of 10 antibiotics to 3 plant species and found a range of phytotoxicity ( $\mathrm{EC}_{25}$ values) ranging from 3.9 to $>10,000 \mu \mathrm{g} / \mathrm{L}$. In general, where the antibiotics evaluated in this study have been measured in soils, the concentrations ranged between $<1$ and the low $100 \mathrm{~s}$ $\mu \mathrm{g} / \mathrm{kg}$. Compared with the toxicologic thresholds established in the present study, there were few instances where these measured soil concentrations would be expected to exceed the $\mathrm{EC}_{25}$ of a specific antibiotic. However, concentrations in WWTP biosolids and manure have occasionally been measured in concentrations $>1,000 \mu \mathrm{g} / \mathrm{kg}$. 
These values would exceed the $\mathrm{EC}_{25}$ of most of the antibiotics evaluated on D. carota, and a few of the compounds, such as chlortetracycline and levofloxacin, for $L$. sativa and $M$. sativa. This could pose a problem for seedling establishment if biosolid or manure applications to agricultural fields occur shortly before planting, particularly if the amendment is not thoroughly tilled into the soil or applied using more current soil-injection techniques. This could lead to aggregates of antibiotic-associated soil creating local hot spots that the seed or plant root may contact during the critical early stages of plant development. The application of screening assays can provide valuable insight into species sensitivity and serve as a basis by which to screen the potential toxic effects of novel compounds. These low-cost tests should continue to be used on known toxicants but more importantly on emerging pollutants.

Acknowledgments The authors thank the Natural Sciences and Engineering Research Council of Canada for funding and Christina Desrochers, Leilan Baxter, Manuel Villatoro, Jason Kerr, Jacqueline Ho, and Mohammad Ali for laboratory assistance. The authors also like to thank the reviewers for their contributions to this manuscript.

\section{References}

ATSM American Society for Testing, Materials (2003) Standard guide for conducting terrestrial plant toxicity tests. ASTM International, West Conshohocken, PA, pp 1534-1554

Barrett K, Floate K, Jensen J, Robinson J, Tolson N (2009) Assessing the effects of veterinary medicines on the terrestrial environment. In: Crane M, Boxall ABA, Barrett K (eds) Veterinary medicines in the environment. CRC Press, New York, NY, pp 155-177

Basset G, Quinlivan EP, Ziemak MJ, Díaz de la Garza R, Fischer M, Schiffmann $S$ et al (2002) Folate synthesis in plants: the first step of the pterin branch is mediated by a unique bimodular GTP cyclohydrolase I. Proc Nat Acad Sci 99:12489-12494

Basset GJC, Quinlivan EP, Gregory JFI, Hanson AD (2005) Folate synthesis and metabolism in plants and prospects for biofortification. Crop Sci 45:449-453

Batchelder AR (1982) Chlortetracycline and oxytetracycline effects on plant growth and development in soil systems. J Environ Qual 11:675-678

Bowley S (1999) A hitchhiker's guide to statistics in plant biology. Any Old Subject Books, Guelph, ON

Boxall ABA, Johnson P, Smith EJ, Sinclair CJ, Stutt E et al (2006) Uptake of veterinary medicines from soils into plants. J Agric Food Chem 54:2288-2297

Brain RA, Hanson ML, Solomon KR, Brooks BW (2008a) Aquatic plants exposed to pharmaceuticals: effects and risks. In: Whitacre DM (ed) Reviews of environmental contamination and toxicology. Springer, New York, NY, pp 67-115

Brain RA, Ramirez AJ, Fulton BA, Chambliss CK, Brooks BW (2008b) Herbicidal effects of sulfamethoxazole in Lemna gibba: using p-aminobenzoic acid as a biomarker of effect. Environ Sci Technol 42:8965-8970

Daughton CG, Ternes TA (1999) Pharmaceuticals and personal care products in the environment: agents of subtle change? Environ Health Perspect 107:907-938
Environment Canada (2005) Biological test method: test for measuring emergence and growth of terrestrial plants exposed to contaminants in soil. Method Development and Applications Section, Environmental Technology Centre, Ottawa, ON, Canada, pp 1-131

Farkas MH, Berry JO, Aga DS (2008) Antibiotic transformation in plants via glutathione conjugation. In: Aga DS (ed) Fate of pharmaceuticals in the environment and in water treatment systems. CRC Press, New York, NY, pp 199-213

Floate KD, Wardhaugh KG, Boxall ABA, Sherratt TN (2005) Fecal effects of veterinary parasiticides: non-target effects in the pasture environment. Ann Rev Entomol 50:153-179

Gambonnet B, Jabrin S, Ravanel S, Karan M, Douce R, Rébeillé F (2001) Folate distribution during higher plant development. J Sci Food Agric 81:835-841

Göbel A, Thomsen A, McArdell CS, Joss A, Giger W (2005) Occurrence and sorption behavior of sulfonamides, macrolides, and trimethoprim in activated sludge treatment. Environ Sci Technol 39:3981-3989

Haller MY, Müller SR, McArdell CS, Alder AC, Suter MJ-F (2002) Quantification of veterinary antibiotics (sulfonamides and trimethoprim) in animal manure by liquid chromatographymass spectrometry. J Chromatogr A 952:111-120

Halling-Sørensen B, Nielsen SN, Lanzky PF, Ingerslev F, Holten LHC, Jørgensen SE (1998) Occurrence, fate and effects of pharmaceutical substances in the environment-a review. Chemosphere 36:357-393

Kapustka LA (1997) Selection of phytotoxicity tests for use in ecological risk assessments. In: Wang W, Gorsuch JW, Hughes JS (eds) Plants for environmental studies. Lewis, CRC Press, Boca Raton, FL, pp 515-548

Kumar K, Gupta SC, Chander Y, Singh AK (2005a) Antibiotic use in agriculture and its impact on the terrestrial environment. Adv Agron 87:1-54

Kumar K, Gupta SC, Baidoo SK, Chander Y, Rosen CJ (2005b) Antibiotic uptake by plants from soil fertilized with animal manure. J Environ Qual 34:2082-2083

Migliore L, Civitareale C, Cozzolino S, Casoria P, Brambilla G, Gaudio L (1998) Laboratory models to evaluate phytotoxicity of sulphadimethoxine on terrestrial plants. Chemosphere 37:2957-2961

Migliore L, Cozzolino S, Fiori M (2003) Phytotoxicity to and uptake of enrofloxacin in crop plants. Chemosphere 52:1233-1244

Nickell LG, Gordon PN (1961) Effects of the tetracycline antibiotics, their degradation products, derivatives and some synthetic analogs on the growth of certain plant systems. Antimicrob Agents Ann 1960:588-593

Pope L, Boxall A, Corsing C, Halling-Sorensen B, Tait A, Topp E (2009) Exposure assessment of veterinary medicines in terrestrial systems. In: Crane M, Boxall ABA, Barrett $\mathrm{K}$ (eds) Veterinary medicines in the environment. CRC Press, New York, NY, pp 129-153

SAS Institute (2003) SAS Statistical Software (Version 9.1.3). Cary, $\mathrm{NC}$

Schneider RJ (2008) Plant uptake of pharmaceuticals from soil determined by ELISA. In: Aga DS (ed) Fate of pharmaceuticals in the environment and in water treatment systems. CRC Press, New York, NY, pp 179-198

Shapiro SS, Wilk MB (1965) An analysis of variance test for normality (complete samples). Biometrika 52:591-611

Sithole BB, Guy RD (1987a) Models for tetracycline in aquatic environments. I. Interaction with bentonite clay systems. Water Air Soil Pollut 32:303-314

Sithole BB, Guy RD (1987b) Models for tetracycline in aquatic environments. II. Interactions with humic substances. Water Air Soil Pollut 32:315-321 
Stephenson GL, Koper N, Atkinson GF, Solomon KR, Scroggins RP (2000) Use of nonlinear regression techniques for describing concentration-response relationships of plant species exposed to contaminated site soils. Environ Toxicol Chem 19:2968-2981

Systat Software Inc (2004) SigmaPlot for Windows (Version 9.01). Point Richmond, CA

Thiele-Bruhn S (2003) Pharmaceutical antibiotic compounds in soils̄a review. J Plant Nut Soil Sci 166:145-167

United States Environmental Protection Agency (1996a) Ecological Effects Test Guidelines: OPPTS 850.4100 Terrestrial Plant Toxicity, Tier I (Seedling Emergence) EPA 712-C-96-153
United States Environmental Protection Agency (1996b) Ecological Effects Test Guidelines: OPPTS 850.4150 Terrestrial Plant Toxicity, Tier I (Vegetative Vigor) EPA 712-C-96-163

Wang W (1992) Use of plants for the assessment of environmental contaminants. Rev Environ Contam Toxicol 126:87-127

Wang X, Sun C, Gao S, Wang L, Shuokui H (2001) Validation of germination rate and root elongation as an indicator to assess phytotoxicity with Cucumis sativus. Chemosphere 44: $1711-1721$ 